\title{
Recent advances in crosslinking chemistry of biomimetic poly(ethylene glycol) hydrogels
}

\author{
Chien-Chi Lin \\ Department of Biomedical Engineering, Purdue School of Engineering and Technology, Indiana \\ University-Purdue University Indianapolis, Indianapolis, IN. 46202, USA
}

\section{Abstract}

The design and application of biomimetic hydrogels have become an important and integral part of modern tissue engineering and regenerative medicine. Many of these hydrogels are prepared from synthetic macromers (e.g., poly(ethylene glycol) or PEG) as they provide high degrees of tunability for matrix crosslinking, degradation, and modification. For a hydrogel to be considered biomimetic, it has to recapitulate key features that are found in the native extracellular matrix, such as the appropriate matrix mechanics and permeability, the ability to sequester and deliver drugs, proteins, and or nucleic acids, as well as the ability to provide receptor-mediated cell-matrix interactions and protease-mediated matrix cleavage. A variety of chemistries have been employed to impart these biomimetic features into hydrogel crosslinking. These chemistries, such as radicalmediated polymerizations, enzyme-mediated crosslinking, bio-orthogonal click reactions, and supramolecular assembly, may be different in their crosslinking mechanisms but are required to be efficient for gel crosslinking and ligand bioconjugation under aqueous reaction conditions. The prepared biomimetic hydrogels should display a diverse array of functionalities and should also be cytocompatible for in vitro cell culture and/or in situ cell encapsulation. The focus of this article is to review recent progress in the crosslinking chemistries of biomimetic hydrogels with a special emphasis on hydrogels crosslinked from poly(ethylene glycol)-based macromers.

\section{Keywords}

Biomimetic hydrogels; poly(ethylene glycol); bioconjugation; photopolymerization; click chemistry; enzymatic crosslinking; supramolecular assembly

\section{Introduction}

Biomimetic hydrogels are a class of water-imbibing but insoluble polymer networks that present aspects of native extracellular matrix (ECM) to the surrounding or encapsulated cells. These aspects include the ability to emulate native matrix mechanics, sequester and deliver growth factors, as well as provide cell-matrix interactions such as ligand-receptor binding and protease-medicated matrix cleavage. ${ }^{[1-4]}$ To mimic matrix mechanics, one can simply adjust the degree of network crosslinking of a hydrogel. ${ }^{[5-11]}$ Growth factor

To whom correspondence should be addressed: Chien-Chi Lin, Ph.D., Assistant Professor, Department of Biomedical Engineering, Indiana University-Purdue University Indianapolis, Indianapolis, IN 46202, Phone: 317-274-0760, Fax: 317-278-2455, lincc@iupui.edu. 
sequestration is often achieved by the covalent immobilization of 'affinity ligands' (e.g., heparin, affinity peptides, small molecular weight ligands, and aptamers) in the network. ${ }^{[2,12-17]}$ The presentation of receptor-binding ligands (e.g., Arg-Gly-Asp peptide, often as network-immobilized pendent motifs) induces receptor-mediated intracellular signaling that is important for maintaining or guiding cell viability and function. ${ }^{[3,18,19]}$ Furthermore, the presence of protease-sensitive substrates (e.g. matrix metalloproteinases (MMPs) cleavable peptides, often serve as a gel crosslinker) permits cell-mediated local matrix cleavage and subsequent cell fate processes, which include migration, extension of cellular processes, and proliferation. ${ }^{[4,20,21]}$ It is known that matrix mechanics profoundly affect cell fate processes through regulating intracellular tensions. ${ }^{[2-24]}$ Emerging work has also demonstrated that along with matrix degradation, the mechanics of the matrix influence cell spreading and cell fate determination. ${ }^{[25-27]}$ Hydrogels are ideal matrices for this type of study as the mechanical properties of these water-swollen matrices can be easily and sometimes independently tuned to mimic native tissue elasticity and bio-functionality. ${ }^{[28]}$ The overarching goal of creating biomimetic hydrogels is to recapitulate local cell-matrix interactions for improving the outcome of global tissue regeneration and/or to understand fundamental mechanisms by which specific extracellular signals influence cell fate determination.

In the past few decades, significant efforts have been dedicated to the design and synthesis of biomimetic hydrogels for tissue engineering and regeneration medicine applications..$^{[1,3,4,29]}$ Many of these hydrogels are fabricated to present soluble or immobilized proteins/peptides as well as controllable matrix elasticity to cells that are encapsulated within or adhered onto the biomimetic hydrogels. Biomimetic hydrogels can be tailored to allow both two-dimensional (2D) and three-dimensional (3D) cell cultures. ${ }^{[30]}$ Compared with flat, rigid, and 2D tissue culture polystyrene (TCPS) or animal-based 3D matrices (e.g., Matrigel or collagen gel), biomimetic hydrogels composed of synthetic polymers, such as poly(ethylene glycol) or PEG, are more flexible and have tunable material properties. Notable applications of biomimetic hydrogels include preservation and differentiation of stem/progenitor cells, exploration of tumor cell migration, invasion, drug responsiveness, and epithelial-mesenchymal transition (EMT), as well as tissue/organ regeneration. The goal of this article is to review some important hydrogel crosslinking chemistries and to provide an update on recent advances in the fabrication of PEG-based biomimetic hydrogels.

\section{Functionalization of PEG-based biomimetic hydrogels using photopolymerizations Chain-growth photopolymerizations}

PEG-based hydrogels possess tissue-like elasticity, high water content, solute permeability, cytocompatibility, and biocompatibility. ${ }^{[1,31]}$ These preferential properties have rendered PEG-based hydrogels highly useful in a variety of biomedical applications, including the controlled release of therapeutically relevant agents and the encapsulation and delivery of cells for immuno-isolation or cell-based therapy ${ }^{\left[{ }^{[32]}\right.}$ Since the chemical makeup of PEG ($\left.\left(\mathrm{CH}_{2} \mathrm{CH}_{2} \mathrm{O}\right)_{\mathrm{n}^{-}}\right)$contains no biological recognition site, modification of PEG-based hydrogels 
is required to render the otherwise inert network biomimetic and cell-responsive. ${ }^{[33]}$ One classic example of functionalizing PEG hydrogels is through co-polymerization of functionalized (e.g., acrylated or methacrylated) peptides during the network crosslinking. ${ }^{[18,34,35]}$ Propagation of radicals (generated from a cleavage type photoinitiator) on vinyl groups results in simultaneous network crosslinking and peptide immobilization (Figure 1A). Acrylated or methacrylate peptides (Figure 1B) can be easily co-polymerized within PEG-diacrylate (PEGDA) or PEG-dimethacrylate (PEGDMA) hydrogels through chain-growth homo-polymerization. Hern and Hubbell used N-hydroxysuccinimidyl (NHS)activated esters (attached either directly to acrylic acid or with a PEG spacer) to introduce an acrylate moiety to the $\mathrm{N}$-terminal $\mathrm{a}$-amine of the peptide. ${ }^{[18]}$ These acrylated peptides can be co-polymerized with PEGDA to form cell-adhesive or bioactive PEG hydrogels. This approach will continue to be an important method of functionalizing PEG hydrogels due to its simplicity. However, two caveats of this approach are as follows: (1) the pendent peptides are co-polymerized within hydrophobic poly(acrylate) or poly(methacrylate) kinetic chains and may have decreased accessibility to the co-encapsulated cells and (2) the immobilization efficiencies of (meth)acrylate-based pendent peptides are generally low $(\sim 60 \%)^{[19,36]}$ and the sol fraction of the bioactive peptides may cause undesired biological responses in the co-encapsulated cells.

The co-polymerization of pendent peptides within PEG hydrogels provides binding sites in the gels for cell surface receptor activation. To render PEG-based hydrogels truly cell responsive, protease sensitivity must also be integrated in the design of a biomimetic hydrogel. PEG hydrogels crosslinked from PEGDA or PEGDMA are hydrolytically and proteolytically stable on therapeutically relevant time scales. To render the covalently crosslinked PEG hydrogels degradable, segments of degradable motifs can be incorporated in the macromer backbone. ${ }^{[32,37]}$ For example, the polymerization of acrylated PLA-PEGPLA macromers yields hydrolytically degradable hydrogels with predictable gel degradation rates. ${ }^{[32,38,39]}$ Protease responsiveness can be integrated into PEG-based hydrogels through crosslinking with known peptide substrates for selective proteases. For example, heterobifunctional PEG macromers such as acrylate-PEG-NHS were used to react with MMPsensitive peptides (e.g., $\mathrm{NH}_{2}$-GPQG $\downarrow$ IWGQK) through nucleophilic addition to primary amines, thus producing a homopolymerizable PEG macromer with protease sensitivity (Figure 1C). ${ }^{[40]}$ Cells encapsulated within this type of hydrogel network were able to remodel their local matrix through protease secretion. While the protease sensitivity of this type of chain-growth PEG hydrogel can be tuned by adjusting the amount of protease sensitive macromer (i.e., acryl-peptide-PEG-peptide-acryl) added during network crosslinking, the accessibility of protease sensitive sections of the macromer to the coencapsulated cells might be limited because of the presence of poly(acrylate) kinetic chains following crosslinking. Another limitation of this system is that the NHS on acrylate-PEGNHS might react with bioactive lysine residues that are present within the protease sensitive sequence.

\section{Step-growth photopolymerizations}

PEG-based hydrogels can be prepared by step-growth photopolymerization (Figure 2A), which yields gels with more homogeneous network structures and better mechanical 
properties compared to chain-growth polymerized gels with similar macromer content. $^{[41,42]}$ The use of photopolymerization permits not only rapid gelation (gel points within seconds), but also spatial-temporal control over gelation kinetics. The crosslinking of PEG-based step-growth hydrogels requires the use of macromers with an average functionality of greater than two. ${ }^{[43,44]}$ Anseth and colleagues developed a radical-mediated and step-growth photopolymerization scheme, termed thiol-norbornene photopolymerization, for forming biomimetic step-growth PEG hydrogels. ${ }^{[45]} \mathrm{A}$ multi-arm PEG macromer functionalized with norbornene was used to react orthogonally with thiolcontaining bi-functional peptides via long wavelength ultraviolet (UV) light mediated stepgrowth photopolymerization and to form hydrogels. The peptide crosslinker contains a sequence that can be cleaved by MMPs and is flanked by terminal cysteine residues (e.g., $\underline{\mathrm{CGPQG}} \downarrow$ IWGQC$)$. The additional cysteines permit a radical-mediated thiol-norbornene 'photo-click' reaction, while the presence of the MMP-sensitive sequence allows cellmediated network cleavage to accommodate cellular processes such as migration, proliferation, and differentiation. ${ }^{[46-48]}$ Other bioactive motifs (e.g., cell adhesive ligands RGDS) can be incorporated within these hydrogels through the conjugation of monocysteine peptides during network crosslinking. The incorporation of pendent bioactive motifs can be easily achieved using peptides bearing a cysteine residue (Figure 2B). Compared to chain-growth acrylate homopolymerizations, step-growth thiol-norbornene gelation has been shown to exhibit better cytocompatibility for radical sensitive cells such as pancreatic $\beta$-cells ${ }^{[41]}$ and chondrocytes. ${ }^{[49]}$ In addition to UV light mediated cross-linking, our own group has developed a visible light (400-700 nm) mediated thiol-norbornene photo-crosslinking method aided by a non-cleavage type photosensitizer eosin-Y. ${ }^{[50-52]}$ Upon visible light exposure, excited eosin-Y molecules deprotonate thiols to give thiyl radicals that subsequently initiate thiol-norbornene reactions to produce step-growth hydrogels with protease sensitivity and cell adhesive properties. The use of visible light eliminates the concerns that UV light, even at long wavelengths and low intensity, could induce cellular damage with biological complications. Readers are directed to a recent review that summarizes the progress of thiol-norbornene hydrogels to-date. ${ }^{[53]}$

\section{Mixed-mode photopolymerizations}

Acrylated PEGs (i.e., linear PEGDA or multi-arm PEG-acrylates) are a unique class of macromer as they can be crosslinked into chain-growth hydrogels (through homopolymerization of PEG-acrylates), ${ }^{[18]}$ step-growth hydrogels (by reacting with thiolcontaining crosslinkers via nucleophilic conjugation addition reaction), ${ }^{[44]}$ or mixed-mode networks (through radical mediated thiol-acrylate polymerization). ${ }^{[54]}$ Peptides or proteins with one or more sulfhydryl groups can also be covalently incorporated in PEG hydrogels through a mixed-mode photopolymerization. ${ }^{[54]}$ Figure 3 shows the mechanism of mixedmode thiol-acrylate polymerization and the incorporation of biomolecules such as peptides. When a higher concentration of thiol is used, the polymerization shifts toward step-growth polymerization. ${ }^{[55]}$ Bioactive peptides, either incorporated as pendant ligands or as part of the crosslinkers, can be easily incorporated as long as cysteine residues are incorporated into the peptide sequences during peptide synthesis. Peptides with additional spacers inserted between the cysteine and bioactive motifs can be used to increase the accessibility of the immobilized peptides to soluble proteins ${ }^{[12,16]}$ or to enhance mesenchymal stem cell 
viability in PEG hydrogels. ${ }^{[54]}$ This class of hydrogels can be prepared via either long-wave UV light $(365 \mathrm{~nm})^{[56]}$ or visible light $(400-700 \mathrm{~nm})^{[57]}$ initiation as long as an appropriate initiator is used (e.g., type-1 initiator for UV-mediated crosslinking and type-2 initiator for visible light-mediated crosslinking). It can be noted that mixed-mode hydrogels polymerized from acrylated/methacrylated macromers and thiol-containing crosslinkers contain hydrolytically labile thioether ester bonds. ${ }^{[36,58]}$ Hydrolysis of these ester bonds may not only facilitate cell spreading and viability but may also lead to early disintegration of the gel network. Moreover, the immobilization efficiency of acrylated peptides $(\sim 60 \%)$ has been shown to be lower than that of thiolated peptides $(\sim 80-90 \%) .{ }^{[58]}$

\section{Enzyme-mediated crosslinking of biomimetic hydrogels}

Several enzymes have been employed for fabricating hydrogels in biomedical applications. For example, horseradish peroxidase (HRP) catalyzes the formation of carbon-carbon bond or carbon-oxygen bond in substrates, such as phenols or anilines, in the presence of hydrogen peroxide $\left(\mathrm{H}_{2} \mathrm{O}_{2}\right)$. Similarly, glucose oxidase (GOX), when mixed with glucose and dissolved oxygen, generates gluconolactone and $\mathrm{H}_{2} \mathrm{O}_{2}$ that is further reduced into hydroxyl ions $(\mathrm{OH}-)$ and hydroxyl radicals $(\bullet \mathrm{OH})$ in the presence of ferrous ions $\left(\mathrm{Fe}^{2+}\right)$. When sufficient vinyl monomers are present in the solution, hydroxyl radicals initiate chaingrowth polymerization to form a covalently crosslinked hydrogel. ${ }^{[59-61]}$ Except for a few examples, ${ }^{[62,63]}$ the cyto- and bio-compatibility of hydrogels crosslinked by HRP or GOX is adversely affected due to the requirement for (in the case of HRP) or generation of (in the case of GOX) $\mathrm{H}_{2} \mathrm{O}_{2}$. While past efforts have demonstrated the unique biomedical applications of PEG-based hydrogels crosslinked by enzymatic activity of HRP or GOX, the use of these enzymes to prepare biomimetic hydrogels that have both cell adhesiveness and protease sensitivity has attracted less attention.

Thrombin is a critical enzyme in the coagulation cascade. In the presence of factor XIIIa, an activated transglutaminase, thrombin converts soluble fibrinogen into an insoluble fibrin clot. Factor XIIIa catalyzes an acyl-transfer reaction between the $\gamma$-carboxamide group of protein bound glutaminyl residues and the amino group of lysine residues to form covalent isopeptide bridges. Lutolf $e$ al. harnessed this efficient reaction and developed biomimetic hydrogels capable of being degraded by enzymatic reactions (Figure 4). ${ }^{[64]}$ In particular, factor XIIIa was utilized to simultaneously cross-link peptide-functionalized PEG and incorporate bioactive peptides. The fusion peptides used contained substrates for factor XIIIa and MMP (e.g., Ac-FKGG-GPQGIWGQ-ERCG-NH ${ }_{2}$ and H-NQEQVSPL-ERCG$\mathrm{NH}_{2}$ ). Some sequences also contained the cell adhesive ligand such as H-NQEQVSPLRGDSPG-NH $\mathrm{N}_{2}$. Among these peptides, the sequence NQEQVSPL was derived from the Nterminus of $\mathrm{a}_{2}$-plasmin inhibitor $\left(\mathrm{a}_{2} \mathrm{PI}_{1-8}\right)$, whereas the sequence Ac-FKGG was optimized for rapid transglutaminase reaction. ${ }^{[65]}$ Upon the addition of factor XIIIa and $\mathrm{Ca}^{2+}$, the two segments containing Lys and Gln residues (i.e., Ac-FKGG and NQEQVSPL, respectively) were catalytically incorporated into a covalent linkage that either has MMP sensitivity (from sequence GPQGIWGQ) or cell adhesiveness (from sequence RGDS). Depending on the gel formulations and enzyme concentrations, the gelation could occur within several minutes and the resulting gels supported spreading, proliferation, and migration of human dermal fibroblasts. Hydrogels crosslinked by factor XIIIa-mediated enzymatic reactions have been 
used in a variety of functional tissue engineering applications. For instance, diverse 3D peptide (e.g., RGD) or protein (e.g., fibrin, VEGF, or PDGF) patterns could be created within PEG-based hydrogels through selective light-activated enzymatic reactions. ${ }^{\text {[66] }}$ hMSCs encapsulated within these dynamically patterned hydrogels showed pattern shapeguided invasion ${ }^{[66]}$ and pattern gradient-induced morphogenesis. ${ }^{[67]}$

Tyrosinase, an enzyme that oxidizes phenols, is another useful enzyme for the crosslinking of hydrogels and underwater bioadhesives. ${ }^{[68]}$ For example, Messersmith and colleagues synthesized 3,4-dihydroxyphenylalanine (DOPA)-modified PEGs, ${ }^{[69]}$ which were crosslinked into hydrogels in the presence of tyrosinase (Figure 5). In another example, Park et al. prepared tyramine-functionalized Pluronic F-127 tri-block copolymers, which were utilized to form self-assembled micelles. ${ }^{[70]}$ The tyramine-conjugated micelles were converted to highly reactive catechol conjugated micelles by tyrosinase. Stable hydrogels were formed due to the cross-linking of Pluronic copolymer micelles. Although these hydrogels did not contain peptide linkers sensitive to cell-secreted proteases or cell adhesion ligands, it will be possible to create such biomimetic matrices using macromers preconjugated with cell adhesive and/or protease sensitive peptides.

\section{Click hydrogels as biomimetic matrices}

'Click' chemistry is used to describe highly efficient, quantitative, and orthogonal reactions between mutually reactive functional groups and it has been used to create functional polymers and network hydrogels for biomedical applications. ${ }^{[71,72]}$ For example, Hubbell and colleagues pioneered the development of PEG-based click hydrogels. They incorporated elegant MMP-sensitive peptide sequences in the hydrogels using nucleophilic Michael-type addition reactions between multi-arm PEG-vinylsulfone and MMP-sensitive peptide crosslinkers with terminal cysteines. ${ }^{[20]}$ Cell adhesive ligands could be easily conjugated using the same Michael-type addition chemistry. Methacrylate, acrylate, and maleimide can also be used to react with bis-cysteine peptides (or multifunctional thiol macromers) for forming cell responsive hydrogels. The major benefit of biomimetic hydrogels formed by nucleophilic conjugation addition reactions is that it does not involve the generation of radicals, which poses major cytocompatibility concerns for radical-sensitive cells. Some of the other notable click chemistries useful in creating biomimetic hydrogels include native chemical ligation, ${ }^{[69,73]}$ oxime-ligand, ${ }^{[74]}$ azide-alkyne addition, ${ }^{[75-78]}$ Diels-Alder reaction, ${ }^{[79]}$ and tetrazine chemistry. ${ }^{[80,81]}$ Similar to the Michael-type conjugation reaction, these chemoselective chemistries are not light dependent and do not require initiators to initiate gel crosslinking. In general, this gelation chemistry lacks spatial-temporal control in gelation kinetics. Furthermore, the reaction rates may be slow at neutral $\mathrm{pH}$ values.

The cross-linking chemistries discussed above have been highly useful for creating biomimetic hydrogels for 3D cell studies. However, most of these chemistries do not permit the dynamic modification of biophysical or biochemical gel properties. The ability to dynamically control gel properties is especially important if one considers that stem and progenitor cells receive complex and dynamic extracellular signals during morphogenesis. Pathological processes in many diseases are also induced by the deregulation of biological signals. It has become increasingly evident that biomaterials capable of mimicking dynamic 
changes of biological cues are powerful tools for studying tissue regeneration. Significant efforts have been dedicated to formulating such dynamic matrices. For example, Shoichet et $a l$. incorporated a nitrobenzyl-protected cysteine in agarose hydrogels to guide 3D cell growth and migration. ${ }^{[82,83]}$ Upon UV exposure, the nitrobenzyl group is removed, revealing the free sulfhydryl group for additional thiol-maleimide conjugation.

Biomolecules can be patterned in 3D to guide cell migration in a spatial-temporally regulated manner.

It will be beneficial if the modification of hydrogel properties can be performed in the presence of cells. For example, Fairbanks et al. developed step-growth thiol-norbornene hydrogels that were crosslinked with an excess amount of norbornene functionalities during network crosslinking. ${ }^{[45]}$ Due to the lack of homopolymerization between norbornene groups and the step-growth nature of the thiol-norbornene reaction, additional thiol-bearing molecules can be patterned within the gel network in the presence of cells. In addition to immobilizing pendant ligands in the presence of cells, one may wish to 'exchange' the ligands to truly recapitulate a dynamic developmental process during tissue morphogenesis. In this regard, an addition-fragmentation-chain transfer reaction was developed to allow controlled and reversible exchange of biochemical ligands within an allyl sulfide functionalized PEG hydrogel (Figure 6). ${ }^{[84]}$

Significant achievements have been made in using orthogonal 'click' chemistry to synthesize biomimetic and dynamically tunable hydrogels. Anseth and colleagues created photolabile hydrogels by incorporating nitrobenzyl groups to the PEG or peptide crosslinkers. ${ }^{\left[{ }^{85-87]}\right.}$ Hydrogels were firstly formed via the redox crosslinking and the gel crosslinking density was decreased in a spatial-temporally controlled manner by adjusting the dosage and location of UV light exposure. When the photolabile group was incorporated on pendant peptides, UV light exposure caused the liberation of these peptides. The system is cytocompatible and the modification of hydrogel properties could be performed in the presence of cells.

Dynamically tunable hydrogels can be prepared by copper-catalyzed azide-alkyne Huisgen cycloaddition reactions (CuAAC). Anseth et al. used this chemistry to fabricate PEG-based hydrogels with patternability. ${ }^{[88]}$ Unfortunately, this reaction is not suitable for in situ cell encapsulation due to the cytotoxicity of copper ions. Furthermore, they developed an alternative approach wherein cyclooctyne, a macromer synthesized originally by the Bertozzi group, ${ }^{[89]}$ was used to react with azides free of cytotoxic metal ions. ${ }^{[76]}$ The metalfree and orthogonal reactivity between a strained cyclooctyne and an azide has allowed researchers to design multifunctional macromers that can be cleaved by cell-secreted proteases and for spatial-temporally controlled conjugation of bioactive motifs. For example, DeForest and Anseth designed a 'sequential-click' approach in a step-growth network to allow the formation of a hydrogel network and modification of its properties through orthogonal conjugation and cleavage of biomimetic peptides. ${ }^{[76-78,90]}$ To expand the utility of dynamic patterning of bioactive motifs in 3D, DeForest and Tirrell recently reported the conjugation and removal of the whole protein within the orthogonally crosslinked network. ${ }^{[91]}$ Two bioorthogonal photochemistries, oxime ligation (Figure 7A) and ortho-nitrobenzyl ester photoscission (Figure 7B), were employed to permit user- 
defined spatial-temporal photo-patterning and removal of whole proteins (Figure 7C). The Anseth group has expanded the toolkits of bio-orthogonal click hydrogels to include: (1) tetrazine-norbornene click reaction (Figure $8 \mathrm{~A})^{[80]}$ and (2) ligation between aliphatic hydrazine with a benzaldehyde- or an aliphatic-aldehyde (Figure 8B). ${ }^{[2]}$ The hydrazinealdehyde click reaction is particularly intriguing as it results in a covalently adaptable network that can respond to cell-induced stress through breaking/reforming elastically active crosslinks while maintaining a macroscopically stable material.

\section{Hydrogels formed from supramolecular assembly}

In addition to the aforementioned covalent crosslinking strategies, PEG-based biomimetic hydrogels can be prepared through macromolecular or supramolecular self-assembly. Macromolecular/supramolecular assembled hydrogels are favorable in many applications because gelation is induced by a purely physical process, which does not rely on radical species. ${ }^{[93]}$ However, compared with covalently crosslinked hydrogels, these gels can have weaker mechanical properties due to the instability of the physical interactions between macromolecules. The most commonly used functionality in macromolecules suitable for forming self-assembled hydrogels are amphiphilic cyclodextrins (CD), including $\alpha-C D, \beta-$ $\mathrm{CD}$, and $\gamma-\mathrm{CD}$, which are composed of 6,7 , and 8 cyclic saccharides, respectively. ${ }^{[94,95]}$ The inner hydrophobic cavity of CDs affords physical interactions with hydrophobic molecules, while the hydrophilic outer surface facilitates the dissolution of the molecules in an aqueous environment. The hydroxyl groups on CDs provide handles for facile chemical modifications, which expand the utility of CDs in biomaterials, drug delivery, and tissue engineering applications.

Supramolecular polymers are increasingly being used as 'building blocks' to fabricate diverse 3D crosslinked polymer networks. For example, macrocyclic CDs and cucurbit[n]urils are routinely used with specific 'guest' molecules to form poly-rotaxanes or catenanes. In particular, CD forms inclusion complexes with hydrophobic guest molecules such as adamantane, azobenzene, ferrocene, and stilbene. ${ }^{[93]}$ In one example, Burdick and colleagues harnessed inclusion complex formation between $\mathrm{CD}$ and adamantane (Ad), which were separately conjugated to hyaluronic acid (HA), to prepare shear-thinning hydrogels for tissue engineering applications. ${ }^{[96-98]}$ The inclusion complexes formed between $\mathrm{CD}$ and Ad led to HA hydrogel formation but the complexes disassembled under shear force, leading to a gel-sol transition. Upon the removal of shear force, the host-guest complexes, and hence the crosslinked hydrogel, re-formed. This new class of supramolecular polymer offers high injectability for implanted biomaterials in a minimally invasive manner. Similar to CDs that bind to hydrophobic molecules, cucurbit[n]uril (CB) binds strongly to guest molecules such as naphthalene and viologen. The complexation between CB and naphthyl-/viologen-functionalized polymers has been used to prepare protein-loaded hydrogels for controlled release applications. ${ }^{[99-101]}$ The aforementioned examples have demonstrated the great utilities of supramolecular assembly in hydrogel formation for biomedical applications.

Supramolecular assembly strategies have also been integrated in the design of PEG-based biomimetic hydrogels. For example, Elisseeff and colleagues have developed a-CD- 
threaded PEGDA hydrogels for tuning the biophysical and biochemical properties of chaingrowth PEG-based hydrogels. ${ }^{[102]}$ Figure 9 illustrates how supramolecular polymers can serve as 'carriers' to impart multiple and orthogonal functionalities to a hydrogel network. The PEG 'necklaces' are decorated/threaded with functionalized aCD to produce hydrogels with tunable mechanics (by changing PEGDA concentration), adhesion (by adjusting the concentration of functionalized aCD but not PEGDA), or chemistry (by introducing aCD with different functional groups, e.g., $-\mathrm{CH}_{3}$ or $-\mathrm{PO}^{4-}$ ). By manipulating the compositions of these supramolecules, multifunctional hydrogels were created for promoting adhesion, proliferation, and differentiation of hMSCs ${ }^{[102]}$ or for studying the roles of matrix mechanics and functions on cancer cell invasion. ${ }^{[103]}$ While not demonstrated in this publication, protease-sensitivity can be integrated into PEG-CD hydrogels by replacing PEGDA with diacrylated PEG-peptide macromers (Figure 1C).

The example shown in Figure 9 exploited modified $\mathrm{CD}$ as carriers of functional or bioactive motifs. The self-assembly between CD and PEG has also been utilized to prepare 'pseudopolyrotaxane' hydrogels. For instance, Cooper-White et al. explored the gelation kinetics and viscoelastic properties of such hydrogels formed by assembly of a-CD and Pluronic polymers (F68 and F127) without or with micelle formation. ${ }^{[104]}$ The formation of 'poly-CDs' at a concentration of over $40 \mathrm{mM}$ of a-CD $\left(25^{\circ} \mathrm{C}\right)$ is critical in this physical gelation/assembly system. The threading of Pluronic polymers into pre-assembled poly-CDs leads to gelation (Figure 10A). In the presence of Pluronic micelles, however, the threading of poly-CDs onto Pluronic polymer becomes more difficult due to the presence of steric hindrance (Figure 10B). The gelation was slower and the gels were weaker in the presence of Pluronic micelles. Although these hydrogels could be formed with strong mechanical properties $\left(\mathrm{G}^{\prime} \sim 10^{6} \mathrm{~Pa}\right)$, they were not stable and dissociated rapidly when immersed in a liquid containing no pseudopolyrotaxane complexes. Cooper-White and colleagues recently reported an improved design of pseudopolyrotaxane hydrogels in which Pluronic/CD assembly was combined with enzyme-mediated crosslinking of tyramine-modified PEG. ${ }^{[105]}$ The gelation was facilitated through a horseradish peroxidase (HRP) and hydrogen peroxide $\left(\mathrm{H}_{2} \mathrm{O}_{2}\right)$ mediated tyramine oxidation (similar to Figure 5). However, careful optimization of enzymatic crosslinking parameters is critical for maintaining acceptable cell viability since $\mathrm{H}_{2} \mathrm{O}_{2}$ is toxic to cells.

\section{Conclusions}

The diversity of biomimetic PEG-based hydrogels has been expanded greatly in recent years owing to the discovery/adaptation of bioconjugation chemistries suitable for biomedical applications. Past efforts have also demonstrated that a hydrogel matrix with multiple functionalities outperforms a single-purpose one for most tissue regeneration applications. While no single chemistry is perfect for all applications, one can certainly adopt and integrate the available chemistries to create suitable biomimetic matrices for a particular tissue regeneration need. It is expected that due to its simplicity, diversity, and proven cytocompatibility in many cell types, radical-mediated hydrogel crosslinking (whether initiated by UV or visible light) will continue to serve as an indispensable chemistry for the design and synthesis of biomimetic hydrogels. The rise of bio-orthogonal chemistry, enzyme-mediated crosslinking, and supramolecular chemistries offer great opportunities for 
scientists to create complex multifunctional hydrogel matrices for addressing biological questions that are otherwise difficult to answer. Lastly, the combination of two or more of these diverse chemistries is anticipated to significantly increase the applicability of biomimetic hydrogels in tissue engineering and regenerative medicine applications.

\section{Supplementary Material}

Refer to Web version on PubMed Central for supplementary material.

\section{Acknowledgement}

This study was supported in parts by the National Institutes of Health (R21CA188911) and a Faculty Startup Fund from Indiana University-Purdue University Indianapolis.

\section{References}

1. Peppas NA, Hilt JZ, Khademhosseini A, Langer R. Adv. Mater. 2006; 18:1345-1360.

2. Lin CC, Anseth KS. Pharma. Res. 2009; 26:631-643.

3. Tibbitt MW, Anseth KS. Biotechnol. Bioeng. 2009; 103:655-663. [PubMed: 19472329]

4. Lutolf MP, Hubbell JA. Nature Biotechnology. 2005; 23:47-55.

5. Wang DA, Williams CG, Li QA, Sharma B, Elisseeff JH. Biomaterials. 2003; 24:3969-3980. [PubMed: 12834592]

6. Bryant SJ, Anseth KS, Lee DA, Bader DL. Journal of Orthopaedic Research. 2004; 22:1143-1149. [PubMed: 15304291]

7. Bryant SJ, Bender RJ, Durand KL, Anseth KS. Biotechnology and Bioengineering. 2004; 86:747755. [PubMed: 15162450]

8. Bryant SJ, Chowdhury TT, Lee DA, Bader DL, Anseth KS. Annals of Biomedical Engineering. 2004; 32:407-417. [PubMed: 15095815]

9. Shu XZ, Liu YC, Palumbo FS, Lu Y, Prestwich GD. Biomaterials. 2004; 25:1339-1348. [PubMed: 14643608]

10. Peyton SR, Raub CB, Keschrumrus VP, Putnam AJ. Biomaterials. 2006; 27:4881-4893. [PubMed: 16762407]

11. Weber LM, Lopez CG, Anseth KS. Journal of Biomedical Materials Research Part A. 2009; 90A: 720-729. [PubMed: 18570315]

12. Lin C-C, Anseth KS. Advanced Functional Materials. 2009; 19:2325-2331. [PubMed: 20148198]

13. Lin C-C, Metters AT. Journal of Biomedical Materials Research Part A. 2007; 83A:954-964. [PubMed: 17580324]

14. Lin C-C, Metters AT. Biomacromolecules. 2008; 9:789-795. [PubMed: 18257528]

15. Lin C-C, Metters AT, Anseth KS. Biomaterials. 2009; 30:4907-4914. [PubMed: 19560813]

16. Lin C-C, Boyer PD, Aimetti AA, Anseth KS. Journal of Controlled Release. 2010; 142:384-391. [PubMed: 19951731]

17. Willerth SM, Johnson PJ, Maxwell DJ, Parsons SR, Doukas ME, Sakiyama-Elbert SE. Journal of Biomedical Materials Research Part A. 2007; 80A:13-23. [PubMed: 16958043]

18. Hern DL, Hubbell JA. Journal of Biomedical Materials Research. 1998; 39:266-276. [PubMed: 9457557]

19. Elbert DL, Hubbell JA. Biomacromolecules. 2001; 2:430-441. [PubMed: 11749203]

20. Lutolf MP, Lauer-Fields JL, Schmoekel HG, Metters AT, Weber FE, Fields GB, Hubbell JA. Proc. Natl. Acad. Sci. USA. 2003; 100:5413-5418. [PubMed: 12686696]

21. Pratt AB, Weber FE, Schmoekel HG, Muller R, Hubbell JA. Biotechnol. Bioeng. 2004; 86:27-36. [PubMed: 15007838] 
22. Peyton SR, Ghajar CM, Khatiwala CB, Putnam AJ. Cell Biochemistry and Biophysics. 2007; 47:300-320. [PubMed: 17652777]

23. Kloxin AM, Kloxin CJ, Bowman CN, Anseth KS. Advanced Materials. 2010; 22:3484-3494. [PubMed: 20473984]

24. Mosiewicz KA, Kolb L, van der Vlies AJ, Lutolf MP. Biomaterials Science. 2014; 2:1640-1651.

25. Huebsch N, Arany PR, Mao AS, Shvartsman D, Ali OA, Bencherif SA, Rivera-Feliciano J, Mooney DJ. Nature Materials. 2010; 9:518-526.

26. Khetan S, Guvendiren M, Legant WR, Cohen DM, Chen CS, Burdick JA. Nature Materials. 2013; $12: 458-465$.

27. Yang C, Tibbitt MW, Basta L, Anseth KS. Nature Materials. 2014; 13:645-652.

28. Tong X, Yang F. Biomaterials. 2014; 35:1807-1815. [PubMed: 24331710]

29. Cushing MC, Anseth KS. Science. 2007; 316:1133-1134. [PubMed: 17525324]

30. DeForest CA, Anseth KS. Annu. Rev. Chem. Biomol. Eng. 2012; 3:421-444. [PubMed: 22524507]

31. Slaughter BV, Khurshid SS, Fisher OZ, Khademhosseini A, Peppas NA. Adv. Mater. 2009; 21:3307-3329. [PubMed: 20882499]

32. Nguyen KT, West JL. Biomaterials. 2002; 23:4307-4314. [PubMed: 12219820]

33. Nuttelman CR, Rice MA, Rydholm AE, Salinas CN, Shah DN, Anseth KS. Prog. Polym. Sci. 2008; 33:167-179. [PubMed: 19461945]

34. West JL, Hubbell JA. Reactive Polymers. 1995; 25:139-147.

35. West JL, Hubbell JA. Macromolecules. 1999; 32:241-244.

36. Hao YT, Shih H, Munoz Z, Kemp A, Lin CC. Acta Biomaterialia. 2014; 10:104-114. [PubMed: 24021231]

37. Lee S-H, Moon JJ, Miller JS, West JL. Biomaterials. 2007; 28:3163-3170. [PubMed: 17395258]

38. Mason MN, Metters AT, Bowman CN, Anseth KS. Macromolecules. 2001; 34:4630-4635.

39. Metters AT, Anseth KS, Bowman CN. Polymer. 2000; 41:3993-4004.

40. Mann BK, Gobin AS, Tsai AT, Schmedlen RH, West JL. Biomaterials. 2001; 22:3045-3051. [PubMed: 11575479]

41. Lin CC, Raza A, Shih H. Biomaterials. 2011; 32:9685-9695. [PubMed: 21924490]

42. Fairbanks BD, Schwartz MP, Halevi AE, Nuttelman CR, Bowman CN, Anseth KS. Adv Mater. 2009; 21:5005-5010. [PubMed: 25377720]

43. Shih H, Lin CC. Biomacromolecules. 2012; 13:2003-2012. [PubMed: 22708824]

44. Metters A, Hubbell J. Biomacromolecules. 2005; 6:290-301. [PubMed: 15638532]

45. Fairbanks BD, Schwartz MP, Halevi AE, Nuttelman CR, Bowman CN, Anseth KS. Adv. Mater. 2009; 21 5005-+

46. Ki CS, Lin T-Y, Korc M, Lin C-C. Biomaterials. 2014; 35:9668-9677. [PubMed: 25176061]

47. Lin T-Y, Ki CS, Lin C-C. Biomaterials. 2014; 35:6898-6906. [PubMed: 24857292]

48. Wang C, Tong X, Yang F. Molecular Pharmaceutics. 2014; 11:2115-2125. [PubMed: 24712441]

49. Roberts JJ, Bryant SJ. Biomaterials. 2013; 34:9969-9979. [PubMed: 24060418]

50. Shih H, Lin CC. Macromol. Rapid Commun. 2013; 34:269-273. [PubMed: 23386583]

51. Shih H, Fraser AK, Lin CC. ACS Appl. Mater. Interfaces. 2013; 5:1673-1680. [PubMed: 23384151]

52. Shih H, Mirmira RG, Lin C-C. Journal of Materials Chemistry B. 2015; 3:170-175.

53. Lin C-C, Ki CS, Shih H. Journal of Applied Polymer Science. 2015; 132

54. Salinas CN, Anseth KS. Macromolecules. 2008; 41:6019-6026.

55. Rydholm AE, Bowman CN, Anseth KS. Biomaterials. 2005; 26:4495-4506. [PubMed: 15722118]

56. Bryant SJ, Nuttelman CR, Anseth KS. Journal of Biomaterials Science-Polymer Edition. 2000; 11:439-457. [PubMed: 10896041]

57. Cruise GM, Hegre OD, Scharp DS, Hubbell JA. Biotechnol. Bioeng. 1998; 57:655-665. [PubMed: 10099245] 
58. Hao Y, Lin C-C. Journal of Biomedical Materials Research Part A. 2014; 102:3813-3827. [PubMed: 24288169]

59. Johnson LM, DeForest CA, Pendurti A, Anseth KS, Bowman CN. Acs Applied Materials \& Interfaces. 2010; 2:1963-1972. [PubMed: 20586415]

60. Hume PS, Bowman CN, Anseth KS. Biomaterials. 2011; 32:6204-6212. [PubMed: 21658759]

61. Shenoy R, Tibbitt MW, Anseth KS, Bowman CN. Chemistry of Materials. 2013; 25:761-767. [PubMed: 23503321]

62. Wang L-S, Chung JE, Chan PP-Y, Kurisawa M. Biomaterials. 2010; 31:1148-1157. [PubMed: 19892395]

63. Menzies DJ, Cameron A, Munro T, Wolvetang E, Grondahl L, Cooper-White JJ. Biomacromolecules. 2013; 14:413-423. [PubMed: 23259935]

64. Ehrbar M, Rizzi SC, Schoenmakers RG, San Miguel B, Hubbell JA, Weber FE, Lutolf MP. Biomacromolecules. 2007; 8:3000-3007. [PubMed: 17883273]

65. Hu BH, Messersmith PB. Journal of the American Chemical Society. 2003; 125:14298-14299. [PubMed: 14624577]

66. Mosiewicz KA, Kolb L, van der Vlies AJ, Martino MM, Lienemann PS, Hubbell JA, Ehrbar M, Lutolf MP. Nature materials. 2013; 12:1072-8.

67. Lienemann PS, Devaud YR, Reuten R, Simona BR, Karlsson M, Weber W, Koch M, Lutolf MP, Milleret V, Ehrbar M. Integrative Biology. 2015; 7:101-111. [PubMed: 25385042]

68. Cencer M, Liu Y, Winter A, Murley M, Meng H, Lee BP. Biomacromolecules. 2014; 15:28612869. [PubMed: 25010812]

69. Lee BP, Dalsin JL, Messersmith PB. Biomacromolecules. 2002; 3:1038-1047. [PubMed: 12217051]

70. Lee SH, Lee Y, Lee S-W, Ji H-Y, Lee J-H, Lee DS, Park TG. Acta Biomaterialia. 2011; 7:14681476. [PubMed: 21111850]

71. Jiang Y, Chen J, Deng C, Suuronen EJ, Zhong Z. Biomaterials. 2014; 35:4969-4985. [PubMed: 24674460]

72. Liu S, Dicker KT, Jia X. Chemical communications (Cambridge, England). 2015; 51:5218-5237.

73. Hu B-H, Su J, Messersmith PB. Biomacromolecules. 2009; 10:2194-2200. [PubMed: 19601644]

74. Grover GN, Lam J, Nguyen TH, Segura T, Maynard HD. Biomacromolecules. 2012; 13:30133017. [PubMed: 22970829]

75. McKinnon DD, Brown TE, Kyburz KA, Kiyotake E, Anseth KS. Biomacromolecules. 2014; 15:2808-2816. [PubMed: 24932668]

76. DeForest CA, Polizzotti BD, Anseth KS. Nat. Mater. 2009; 8:659-664. [PubMed: 19543279]

77. DeForest CA, Sims EA, Anseth KS. Chem. Mater. 2010; 22:4783-4790. [PubMed: 20842213]

78. DeForest CA, Anseth KS. Nat. Chem. 2011; 3:925-931. [PubMed: 22109271]

79. Koehler KC, Alge DL, Anseth KS, Bowman CN. Biomaterials. 2013; 34:4150-4158. [PubMed: 23465826]

80. Alge DL, Azagarsamy MA, Donohue DF, Anseth KS. Biomacromolecules. 2013; 14:949-953. [PubMed: 23448682]

81. Zhang H, Dicker KT, Xu X, Jia X, Fox JM. Acs Macro Letters. 2014; 3:727-731. [PubMed: 25177528]

82. Luo Y, Shoichet MS. Biomacromolecules. 2004; 5:2315-2323. [PubMed: 15530047]

83. Luo Y, Shoichet MS. Nature Materials. 2004; 3:249-253.

84. Gandavarapu NR, Azagarsamy MA, Anseth KS. Advanced Materials. 2014; 26:2521-2526. [PubMed: 24523204]

85. Kloxin AM, Kasko AM, Salinas CN, Anseth KS. Science. 2009; 324:59-63. [PubMed: 19342581]

86. Kloxin AM, Benton JA, Anseth KS. Biomaterials. 2010; 31:1-8. [PubMed: 19788947]

87. Kloxin AM, Tibbitt MW, Kasko AM, Fairbairn JA, Anseth KS. Advanced Materials. 2010; 22 61$+$

88. Polizzotti BD, Fairbanks BD, Anseth KS. Biomacromolecules. 2008; 9:1084-1087. [PubMed: 18351741] 
89. Agard NJ, Prescher JA, Bertozzi CR. Journal of the American Chemical Society. 2004; 126:15046-15047. [PubMed: 15547999]

90. DeForest CA, Anseth KS. Angew. Chem. Int. Ed. 2012; 51:1816-1819.

91. DeForest CA, Tirrell DA. Nat Mater. 2015

92. McKinnon DD, Domaille DW, Cha JN, Anseth KS. Advanced Materials. 2014; 26:865-872. [PubMed: 24127293]

93. Dong R, Zhou Y, Huang X, Zhu X, Lu Y, Shen J. Advanced Materials. 2015; 27:498-526. [PubMed: 25393728]

94. Zhang J, Ma PX. Advanced Drug Delivery Reviews. 2013; 65:1215-1233. [PubMed: 23673149]

95. Schmidt BVKJ, Hetzer M, Ritter H, Barner-Kowollik C. Progress in Polymer Science. 2014; 39:235-249.

96. Guvendiren M, Lu HD, Burdick JA. Soft Matter. 2012; 8:260-272.

97. Rodell CB, Kaminski AL, Burdick JA. Biomacromolecules. 2013; 14:4125-4134. [PubMed: 24070551]

98. Rodell CB, MacArthur JW Jr, Dorsey SM, Wade RJ, Wang LL, Woo YJ, Burdick JA. Advanced Functional Materials. 2015; 25:636-644.

99. Appel EA, Biedermann F, Rauwald U, Jones ST, Zayed JM, Scherman OA. Journal of the American Chemical Society. 2010; 132:14251-14260. [PubMed: 20845973]

100. Appel EA, Loh XJ, Jones ST, Biedermann F, Dreiss CA, Scherman OA. Journal of the American Chemical Society. 2012; 134:11767-11773. [PubMed: 22758793]

101. Appel EA, Loh XJ, Jones ST, Dreiss CA, Scherman OA. Biomaterials. 2012; 33:4646-4652. [PubMed: 22459194]

102. Singh A, Zhan J, Ye Z, Elisseeff JH. Advanced Functional Materials. 2013; 23:575-582.

103. Beck JN, Singh A, Rothenberg AR, Elisseeff JH, Ewald AJ. Biomaterials. 2013; 34:9486-9495. [PubMed: 24044993]

104. Pradal C, Jack KS, Grondahl L, Cooper-White JJ. Biomacromolecules. 2013; 14:3780-3792. [PubMed: 24001031]

105. Pradal C, Grondahl L, Cooper-White JJ. Biomacromolecules. 2015; 16:389-403. [PubMed: 25469767] 
A.

$\mathrm{PI}$

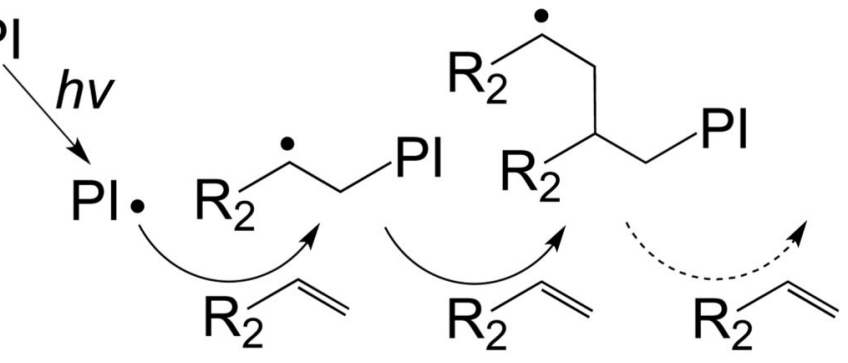

B.<smiles>C=CC(=O)NC(=O)N[R6]#[SH]</smiles>

C.

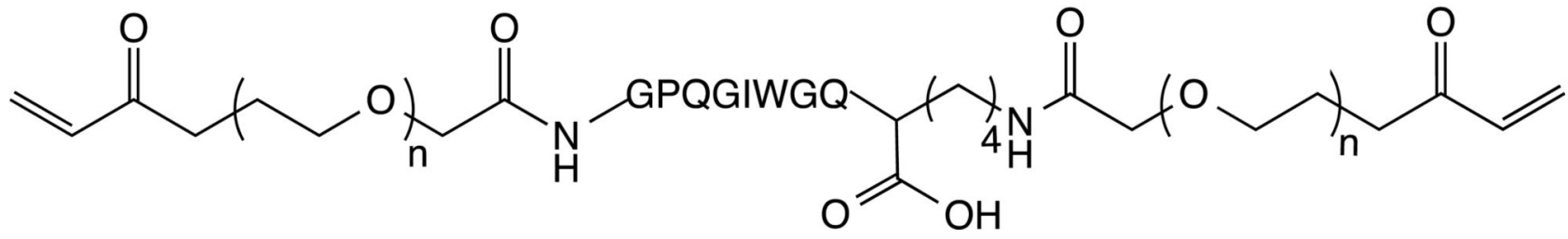

Figure 1.

(A) Schematic of chain-growth photopolymerization for forming peptide-immobilized hydrogels (PI: photopolymerization, $h v$ : light source). (B) Acrylated RGDS peptide for copolymerization into PEGDA hydrogels. (C) Schematic of an acrylate-PEG-GPQGIWGQKPEG-acrylate crosslinker. 
A.

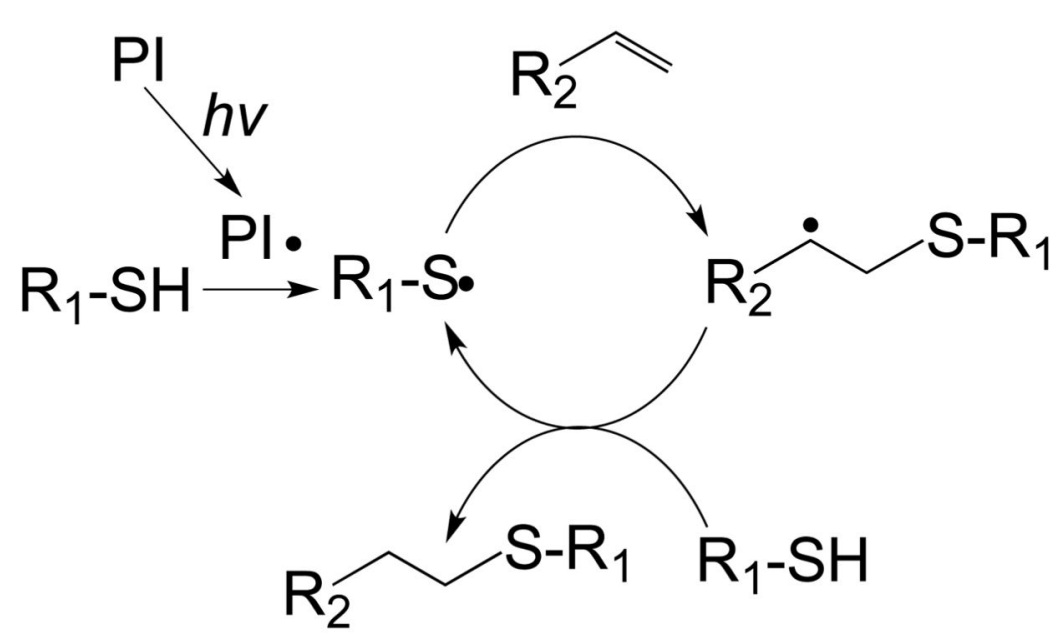

B.

Figure 2.

Schematic of step-growth photopolymerization for forming hydrogels (PI: photopolymerization, $h v$ : light source). (B) Cysteine-containing RGDS peptide for copolymerization into the step-growth hydrogel (N-terminal acetylated peptide). 


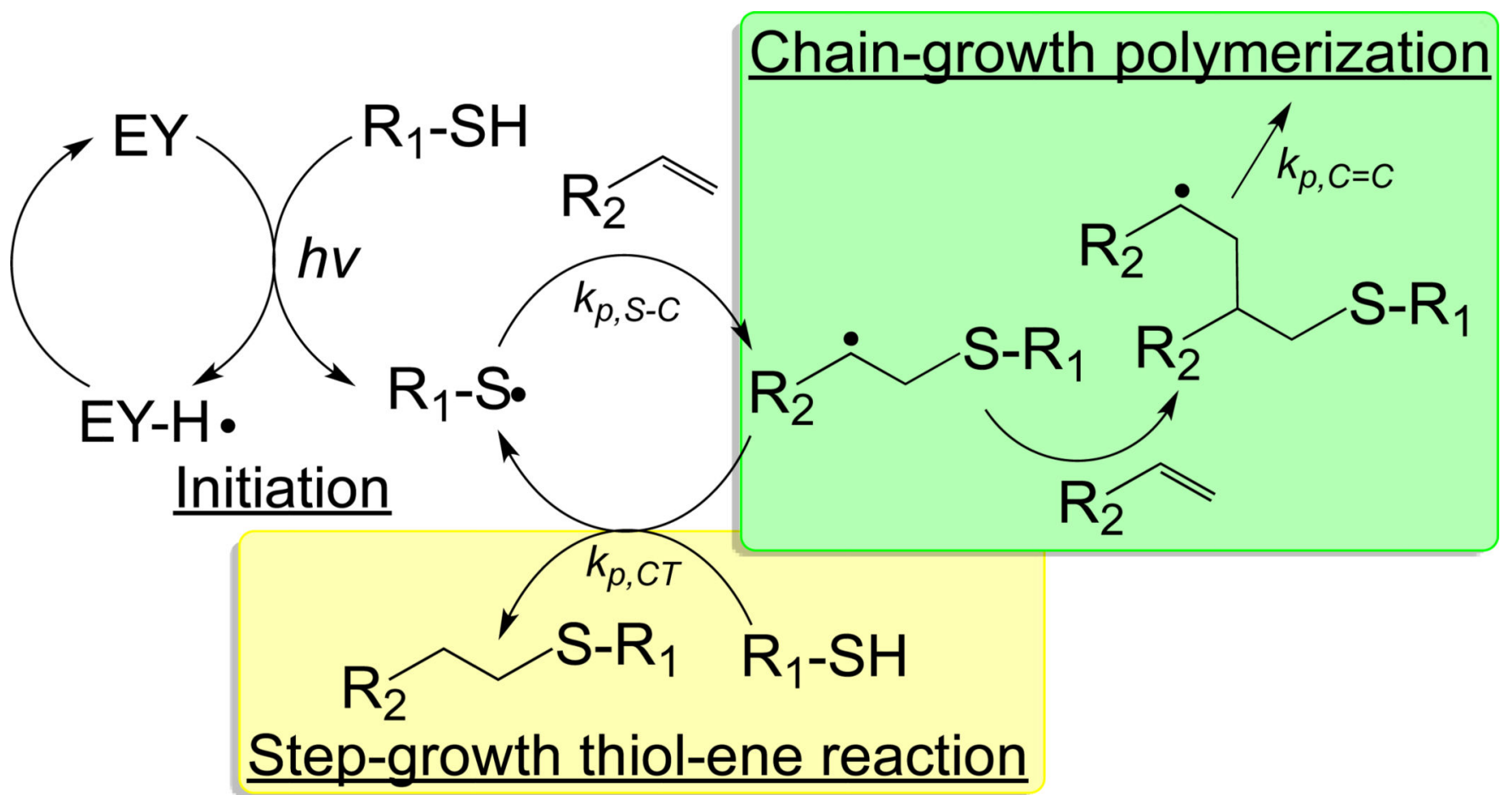

Figure 3.

Schematic of a visible light initiated mixed-mode photopolymerization for forming hydrogels (EY: eosin-Y; $h v$ : visible light source; $k_{p, S-C}, k_{p, C=C}, k_{p, C T}$ : kinetic constants for thiol-carbon radical propagation, carbon-carbon radical propagation, and chain-transfer, respectively.). ${ }^{[36]}$ 

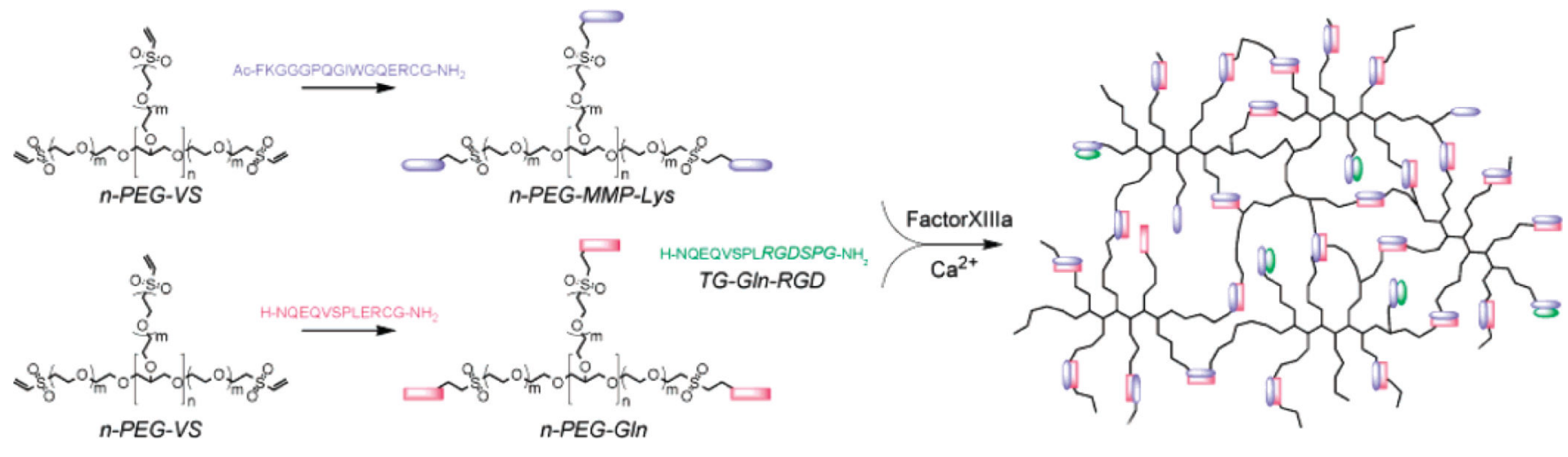

Figure 4.

Schematic of factor XIIIa-catalyzed formation of a PEG-peptide biomimetic hydrogel.

Factor XIIIa was used to cross-link two PEG-peptide conjugates (n-PEG-MMP-Lys and nPEG-Gln) in combination with a cell adhesion peptide (TG-Gln-RGD) to form multifunctional biomimetic hydrogels. Reprinted with permission from ${ }^{[64]}$. Copyright 2007, American Chemical Society. 


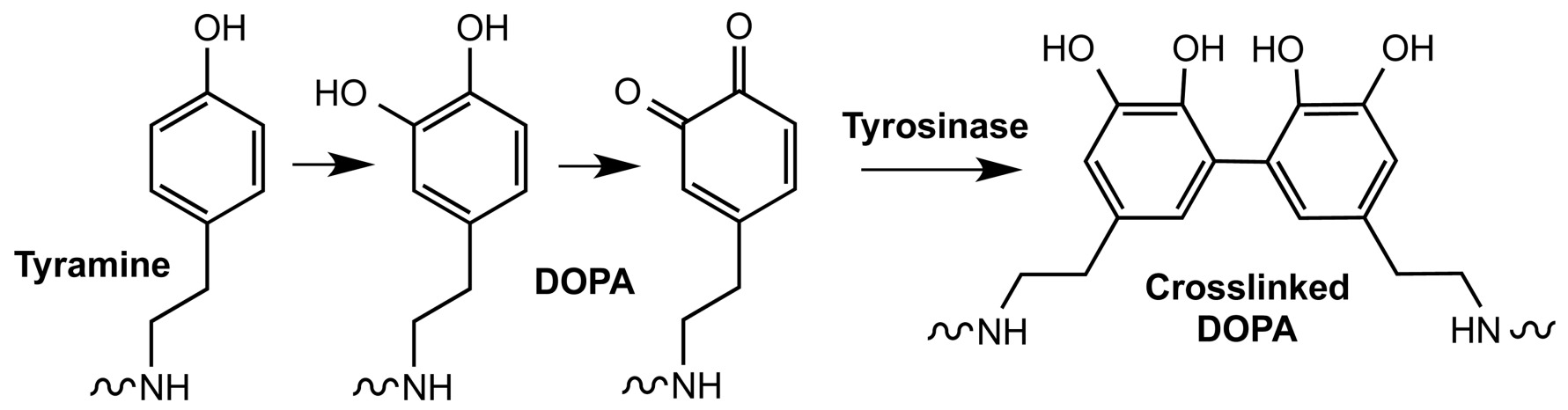

Figure 5.

Oxidative conversion of tyramine to a catechol and subsequent crosslinking by tyrosinase. 
<smiles>[R][R]CS[R][R]SCC(CS[R])CS[R]</smiles>

Figure 6.

Mechanism of addition fragmentation chain transfer of an allyl sulfide functional group upon attack by a thiyl radical. Redrawn with permission from ${ }^{\text {[84] }}$. Copyright 2014 , John Wiley and Sons. 
A.

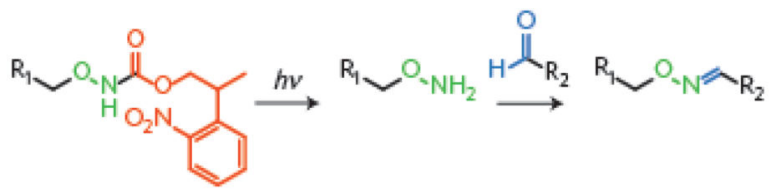

B.

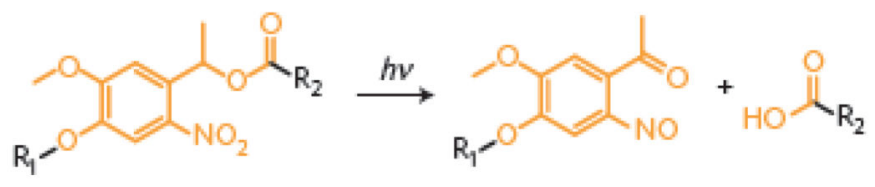

C.

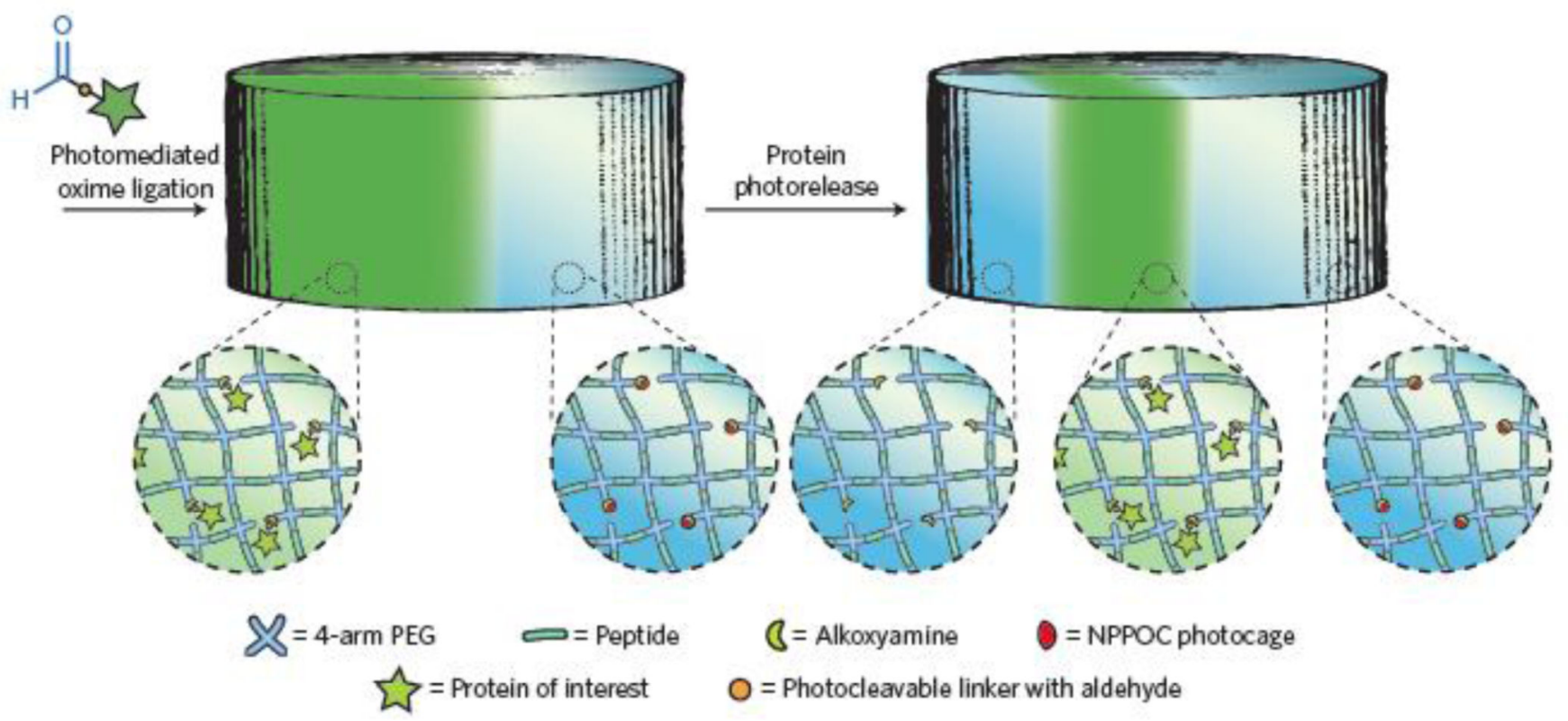

Figure 7.

(A) Caged alkoxyamines undergo irreversible $\beta$-elimination upon exposure to 365 or $740 \mathrm{~nm}$ light. The liberated alkoxyamines react with aldehyde-functionalized proteins (R2) to form oxime linkages. (B) o-Nitrobenzyl ester ( $\mathbf{o N B}$ ) moieties linking the protein of interest (R1) and the hydrogel (R2) undergo photocleavage upon exposure to $365 \mathrm{~nm}$ or $740 \mathrm{~nm}$ light. (C) Schematic of the photo-reversible patterning strategy. NHS-oNB-CHO-functionalized proteins are first tethered to the gel through photo-mediated oxime ligation and subsequently removed on secondary light exposure. Reprinted with permission from ${ }^{[91]}$. Copyright 2015, Nature Publishing Group. 
A.

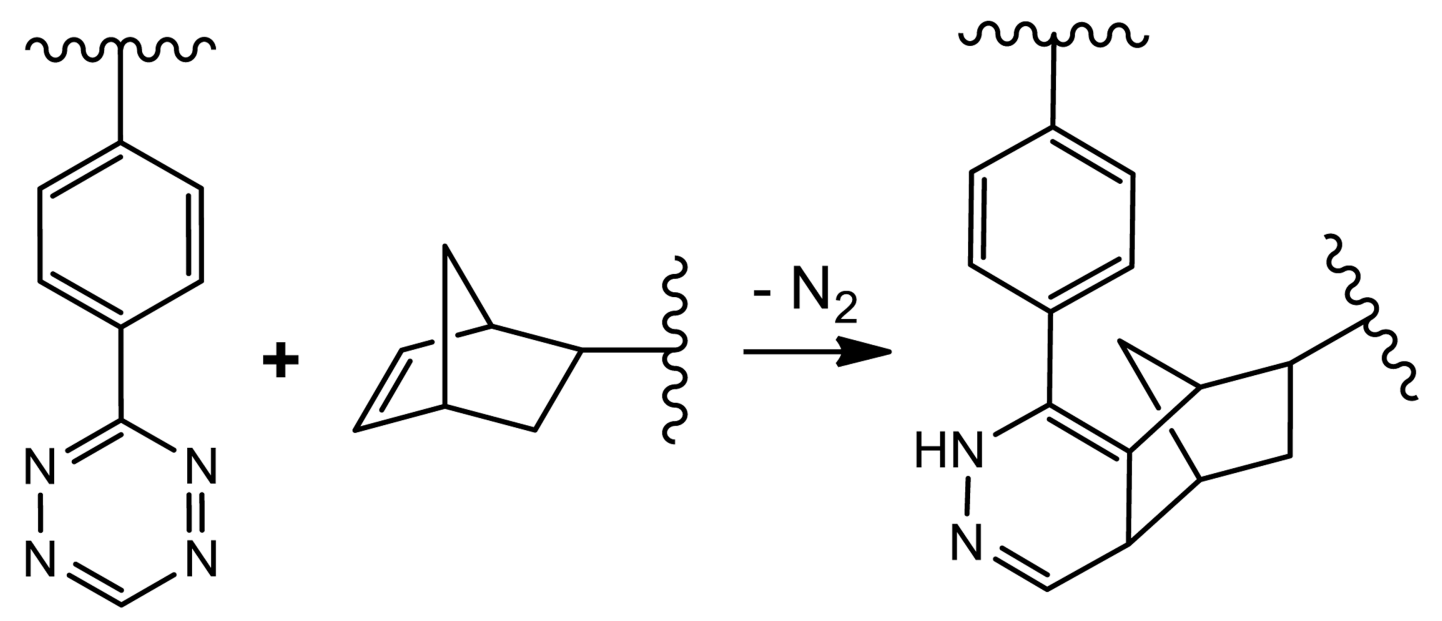

B.<smiles>NNSC1CCSCC1SC=O</smiles>

Figure 8.

(A) Tetrazine-norbornene click reaction; (B) covalently adaptable network formed by Nmethyl hydrazine-butyraldehyde ligation. 


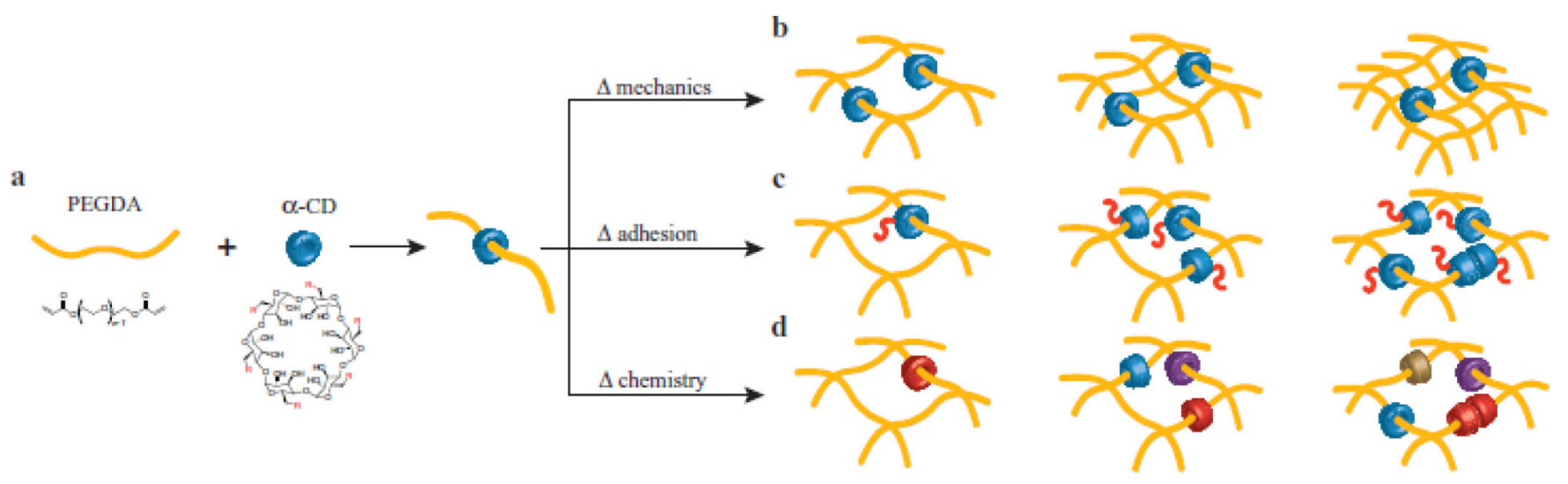

Figure 9.

Schematic of a molecular-necklace system to create multifunctional hydrogels with independent control of gel mechanics, cell adhesiveness, and chemical functionality. a) Inclusion complex between PEGDA and $\mathrm{a}-\mathrm{CD}$ ( $\mathrm{R}=$ hydroxyl or other functional groups). $\mathrm{b}$ ) Tuning the mechanical properties of an a-CD-PEG hydrogel independent of a-CD concentration. c) Tuning the concentration of a cell adhesive peptide through threading different amount of functionalized a-CD independent of gel cross-linking density. d) Tuning the chemical functionality of a hydrogel through threading aCD with different functional groups (i.e., hydrophobic, hydrophilic or charged groups). Reprinted with permission from ${ }^{[102]}$. Copyright 2013, John Wiley and Sons. 


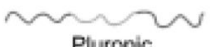

Pluronic

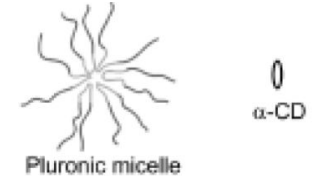

A

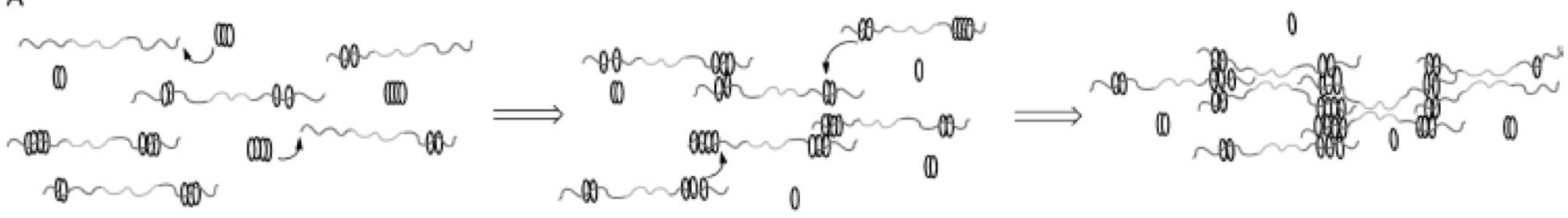

B
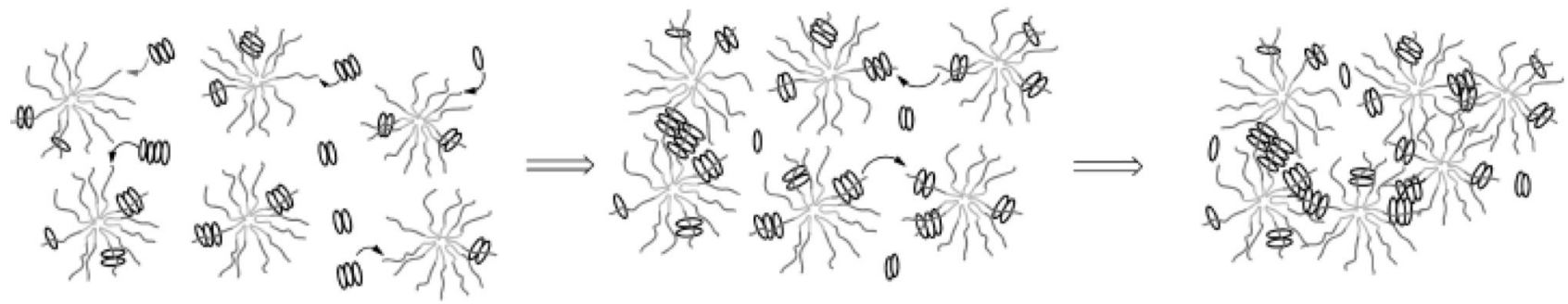

Figure 10.

Temporal gelation mechanism of linear Pluronic (e.g.: F6810 and F6820) or Pluronic micelles (e.g.: F12710) and a-CD. (A) Gelation without micelle formation. (B) Gelation in the presence of micelles. Reprinted with permission from ${ }^{[104]}$. Copyright 2013, American Chemical Society. 